\title{
TP53 genetic polymorphisms, interactions with lifestyle factors and lung cancer risk: a case control study in a Chinese population
}

\author{
Yanli $\mathrm{Li}^{1 \dagger}$, Shen-Chih Chang ${ }^{2 \dagger}$, Rungui $\mathrm{Niu}^{3}$, Li Liu${ }^{4}$, Christina R Crabtree-Ide ${ }^{1}$, Baoxing Zhao ${ }^{4}$, Jianping Shi ${ }^{4}$,

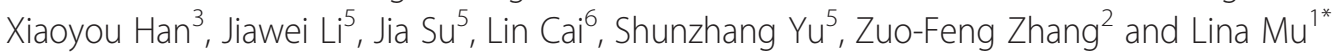

\begin{abstract}
Background: A pathway-based genotyping analysis suggested rs2078486 was a novel TP53 SNP, but very few studies replicate this association. TP53 rs 1042522 is the most commonly studied SNP, but very few studies examined its potential interaction with environmental factors in relation to lung cancer risk. This study aims to examine associations between two TP53 single-nucleotide polymorphisms (SNPs) (rs2078486, rs1042522), their potential interaction with environmental factors and risk of lung cancer.

Methods: A case-control study was conducted in Taiyuan, China. Unconditional logistic regression was used to estimate odds ratios (ORs) and 95\% confidence intervals (95\% Cls). Multiplicative and additive interactions between TP53 SNPs and lifestyle factors were evaluated.

Results: Variant TP53 rs2078486 SNP was significantly associated with elevated lung cancer risk among smokers (OR: 1.70, 95\% Cl: 1.08 - 2.67) and individuals with high indoor air pollution exposure (OR: 1.51, 95\% Cl: 1.00-2.30). Significant or borderline significant multiplicative and additive interactions were found between TP53 rs2078486 polymorphism with smoking and indoor air pollution exposure. The variant genotype of TP53 SNP rs 1042522 significantly increased lung cancer risk in the total population (OR: 1.57, 95\% Cl: 1.11-2.21), but there was no evidence of heterogeneity among individuals with different lifestyle factors.

Conclusions: This study confirmed that TP53 rs2078486 SNP is potentially a novel TP53 SNP that may affect lung cancer risk. Our study also suggested potential synergetic effects of TP53 rs2078486 SNP with smoking and indoor air pollution exposure on lung cancer risk.
\end{abstract}

Keywords: Lung cancer, TP53, Single-nucleotide polymorphism, Chinese population

\section{Background}

Lung cancer is one of the most common cancers and is a leading cause of cancer death in China. It was estimated that by year 2025, more than one million Chinese will be diagnosed with lung cancer per year [1]. Lung cancer mortality increased $465 \%$ during the past 30 years and now is the leading cancer death cause in China [2]. Smoking is regarded as the most important risk factor for lung cancer, and indoor air pollution from cooking

\footnotetext{
* Correspondence: linamu@buffalo.edu

${ }^{\dagger}$ Equal contributors

'Department of Social and Preventive Medicine, School of Public Health and Health Professions, The State University of New York (SUNY) at Buffalo, 273A Farber Hall, Buffalo, New York 14214-8001, USA

Full list of author information is available at the end of the article
}

and heating is another potential risk factor in Chinese population [3]. However, approximately one in ten lifetime smokers develop lung cancer, which implies a possible role for genetic susceptibility in the development of lung cancer [4].

The TP53 tumor suppressor gene plays a critical role in modulating transcription of genes that govern the major defenses against tumor growth, including cell cycle arrest, apoptosis, maintenance of genetic integrity, inhibition of angiogenesis and cellular senescence [5]. The TP53 gene harbors high-frequency, functional single-nucleotide polymorphisms (SNPs) which may alter P53 protein function [6]. Several functional TP53 SNPs have been reported to be associated with risk

\section{Biomed Central}

(c) 2013 Li et al.; licensee BioMed Central Ltd. This is an open access article distributed under the terms of the Creative Commons Attribution License (http://creativecommons.org/licenses/by/2.0), which permits unrestricted use, distribution, and reproduction in any medium, provided the original work is properly cited. 
of developing different human cancers, including lung cancer [7-9].

TP53 rs2078486 SNP was recently identified to be associated with lung cancer risk in lifetime never smokers in a pathway-based genotyping study which evaluated a comprehensive panel of 11,737 SNPs in inflammatorypathway genes [10]. One case-control study conducted among 611 lung cancer cases and 1040 controls in Los Angeles found elevated lung cancer risk associated with the variant genotype of TP53 rs2078486 SNP (doctoral dissertation from Yi Ren Wang) [11]. However this association was not confirmed by another pooled genomewide association study [12]. In addition to lung cancer, TP53 rs2078486 SNP has been also linked with risk of ovarian cancer [13] and schizophrenia [14]. To our knowledge, no case-control study has been conducted in the Asian population to replicate the association of TP53 rs2078486 SNP with lung cancer.

The most studied TP53 SNP rs1042522 is characterized by substitution of Arginine (Arg) by Proline (Pro) at codon 72 (G12139C, Arg72Pro) and may noticeably affect P53 function [15]. However, very few studies examined if there are interactions between Arg72Pro polymorphism and smoking or other lifestyle factors on lung cancer risk.

A case-control study was conducted to examine the associations of TP53 rs2078486 and rs1042522 SNPs with lung cancer risk in a Chinese population and further explore their interactions with some demographic and lifestyle factors.

\section{Methods}

\section{Study participants}

A case-control study was conducted between 2005 and 2007 in Taiyuan city, the capital of Shanxi province, China. The original study population has been described in detail previously [16]. Prior to the initiation of the recruitment, IRB approvals were obtained from Fudan University (IRB\#04-10-0022) and UCLA (IRB\#11-003153), respectively. Lung cancer cases were enrolled from the Shanxi tumor hospital, which admitted about $70 \%$ of the cancer patients from the city. Eligible cases were newly diagnosed lung cancer cases, 20 years of age or older, lived in Taiyuan city for 10 years or more, in stable medical condition and willing to participate. Controls were randomly selected from 13 communities in Taiyuan city. Eligible controls were 20 years of age or older, must have lived in Taiyuan city for 10 years or more, and had no history of cancer or any other serious chronic diseases. A total of 399 lung cancer patients and 466 healthy controls were recruited to participate in this study. Response rates were $89 \%$ for eligible cases and $85 \%$ for eligible controls. Written informed consent was obtained from all study participants.

\section{Data collection}

All cases and controls were interviewed by professional staff to collect information on demographic factors, dietary and cooking habits, active and passive smoking history, alcohol drinking habits, tea drinking habits, residence and housing history, occupational history and related exposure, physical activities and disease history.

\section{Blood sample collection and laboratory analysis of gene polymorphisms}

Blood samples were collected from $97.9 \%$ of cases and 98.9\% of controls. Serum and blood clot were immediately separated and all samples were stored in freezer at $-80^{\circ} \mathrm{C}$. Genomic DNA was extracted using a modified phenolchloroform protocol. Genotyping was performed in the Molecular Epidemiology Laboratory at Department of Epidemiology, School of Public Health at UCLA. TP53 SNP genotyping was performed using Sequenom platform (Sequenom, Inc., San Diego, CA). Polymerase chain reaction (PCR) and extension primers were designed using MassARRAY Assay Design 3.1 software (Sequenom, Inc., San Diego, CA). Genotyping procedures were performed according to the manufacturer's iPLEX Application Guide (Sequenom Inc. SanDiego,CA). For quality control, we included two negative controls $\left(\mathrm{H}_{2} \mathrm{O}\right)$ in each 96-well plate. Around $4.5 \%$ of samples were selected for duplication and the concordance is $99.5 \%$. We found no obvious deviations from Hardy-Weinberg equilibrium for both SNPs (rs2078486: $\chi^{2}=0.19, P=0.6629$; rs1042522: $X^{2}=4.24, P=0.0395$ ) among control subjects. We did not find strong linkage disequilibrium between the two SNPs $\left(D^{\prime}<0.5\right)$ in the current study and this is consistent with previous studies $[17,18]$.

\section{Definition of indoor air pollution index}

An indoor air pollution index was created to integrate the impacts from different types of cooking and heating fuels, use of ventilator in kitchen, windows opening behaviors and secondhand smoke exposure at home on indoor air pollution levels. For each component of this index, a score of ' 0 ' or ' 1 ' represented low or high indoor air pollution, respectively. A summarized score lower than 2 was defined as low indoor air pollution exposure and higher or equal to 2 was defined as high indoor air pollution exposure [16].

\section{Statistical analysis}

Odds ratios (ORs) and 95\% confidence intervals (95\% CIs) were estimated using unconditional logistic regression models to evaluate the independent effects of the two TP53 SNPs. We presented each of the associations in additive, dominant and recessive models, respectively. Potential confounding factors adjusted in the multivariate models included age, education level, annual personal income 
10 years ago, pack-years of smoking, alcohol drinking and tea drinking status. Stratified analyses were conducted among subgroups with different age, gender, smoking status, alcohol and tea drinking status, indoor air pollution exposure and histo-pathological types of lung cancer. Multiplicative interactions of TP53 SNPs with some lifestyle factors were assessed using ORs for interactions by including their product terms in the logistic regression models. Additive interactions were assessed using relative excess risk due to interaction (RERI), as described previously [19]. All statistical analyses were performed using SAS software (version 9.3). Associations were considered statistically significant if the p-value $<0.05$ in the twosided test.

\section{Results}

Basic characteristics of lung cancer cases and controls are presented in Table 1 . No statistically significant differences in age and gender were found between cases and controls. Controls tended to have higher education levels, average annual income and body mass index than cases $(\mathrm{p}<0.0001)$. Lung cancer cases were more likely to be smokers and had higher pack-years of smoking, but were less likely to be current tea drinkers $(\mathrm{p}<0.0001)$ (Table 1).

Table 2 presents the independent associations between the two TP53 SNPs and lung cancer risk in the total study population. No significant associations with lung cancer risk were found for TP53 rs2078486 SNP, despite a tendency towards an elevated lung cancer risk associated with the variant genotype. A significantly increased lung cancer risk was observed among individuals with the homozygous variant genotype (CC) of TP53 SNP rs1042522 (adjusted OR: 1.63, 95\% CI: 1.10 - 2.41), compared with the homozygous wild type (GG). Adjusted ORs for rs1042522 were also statistically significant in the recessive model (adjusted OR: 1.57, 95\% CI: 1.112.21), but not in the dominant model. C allele of TP53 SNP rs1042522 was significantly associated with increased risk of developing lung cancer (adjusted OR: 1.26, 95\% CI: 1.04 - 1.53) (Table 2).

Results from the stratified analyses are presented in Figure 1. Presence of one or both copies of minor allele (TC or CC) of TP53 rs2078486 SNP was significantly or borderline significantly associated with elevated lung cancer risk among older individuals (adjusted OR: 1.53, 95\% CI: 0.97 - 2.41), smokers (adjusted OR: 1.70, 95\% CI: 1.08 - 2.67), alcohol drinkers (adjusted OR: 2.41, 95\% CI: 1.25 - 4.65) and individuals with high indoor air pollution exposure (adjusted OR: 1.51, 95\% CI: 1.00-2.30) (Figure 1). Significant multiplicative and additive interactions were found between the indoor air pollution index and TP53 rs2078486 polymorphism (adjusted OR for interaction: 1.89, 95\% CI:
Table 1 Basic characteristics of cases and controls in Taiyuan lung cancer study

\begin{tabular}{|c|c|c|c|}
\hline Variable & $\begin{array}{l}\text { Cases } \\
\mathrm{N}(\%)\end{array}$ & $\begin{array}{c}\text { Controls } \\
\text { N (\%) }\end{array}$ & $P$ value \\
\hline \multicolumn{4}{|l|}{ Age } \\
\hline$\leq 45$ years & $59(14.8)$ & $83(17.8)$ & \multirow{4}{*}{0.0725} \\
\hline $45-55$ yrs & $96(24.1)$ & $139(29.8)$ & \\
\hline $55-65$ yrs & $111(27.8)$ & $116(25.0)$ & \\
\hline$>65 \mathrm{yrs}$ & $133(33.3)$ & $128(27.4)$ & \\
\hline \multicolumn{4}{|l|}{ Gender } \\
\hline Male & $202(50.6)$ & $234(50.2)$ & \multirow{2}{*}{0.9038} \\
\hline Female & $197(49.4)$ & $232(49.8)$ & \\
\hline \multicolumn{4}{|l|}{ Education } \\
\hline Illiterate & $43(10.8)$ & $23(4.9)$ & \multirow{5}{*}{$<.0001$} \\
\hline Primary school & $106(26.6)$ & $81(17.4)$ & \\
\hline Junior middle school & $124(31.1)$ & $175(37.5)$ & \\
\hline Senior middle school & $68(17.0)$ & $120(25.8)$ & \\
\hline College or higher & $58(14.5)$ & $67(14.4)$ & \\
\hline \multicolumn{4}{|l|}{ Pack years of smoking } \\
\hline Non smokers & $179(44.9)$ & $285(61.2)$ & \multirow{4}{*}{$<.0001$} \\
\hline$<20$ pyrs & $39(9.8)$ & $62(13.3)$ & \\
\hline $20-40$ pyrs & $64(16.0)$ & $72(15.5)$ & \\
\hline$\geq 40$ pyrs & $117(29.3)$ & $47(10.1)$ & \\
\hline \multicolumn{4}{|c|}{ Average income 10 years ago } \\
\hline$<1,000$ yuan & $104(26.1)$ & $106(22.7)$ & \multirow{3}{*}{$<.0001$} \\
\hline $1,000-2,500$ yuan & $236(59.1)$ & $197(42.3)$ & \\
\hline$\geq 2,500$ yuan & $59(14.8)$ & $163(35.0)$ & \\
\hline \multicolumn{4}{|l|}{ BMI $\left(\mathrm{kg} / \mathrm{m}^{2}\right)$} \\
\hline$<18.5$ & $22(5.8)$ & $9(2.0)$ & \multirow{4}{*}{$<.0001$} \\
\hline $18.5-24.9$ & $250(66.3)$ & $259(56.3)$ & \\
\hline $25-29.9$ & $90(23.9)$ & $162(35.2)$ & \\
\hline$\geq 30$ & $15(4.0)$ & $30(6.5)$ & \\
\hline \multicolumn{4}{|l|}{ Alcohol drinking } \\
\hline No & $298(74.7)$ & $345(74.0)$ & \multirow{2}{*}{0.8267} \\
\hline Yes & $101(25.3)$ & $121(26.0)$ & \\
\hline \multicolumn{4}{|l|}{ Tea drinking } \\
\hline No & $242(60.6)$ & $263(56.5)$ & \multirow{3}{*}{$<.0001$} \\
\hline Previous drinkers & $47(11.8)$ & $15(3.2)$ & \\
\hline Current drinkers & 110 (27.6) & $188(40.3)$ & \\
\hline Total & 399 & 466 & \\
\hline
\end{tabular}

Adjusted age, gender, education, pack years of smoking, alcohol drinking, tea drinking and average income 10 years ago.

Significant differences were highlighted in bold.

1.00-3.56, adjusted REPI: 0.90, 95\% CI: 0.11-1.70). There was also some suggestive evidence of multiplicative interaction between smoking and TP53 rs2078486 polymorphism (adjusted OR for interaction: 1.80, 95\% CI: 
Table 2 Associations of TP53 SNPs with lung cancer risk in Taiyuan lung cancer study in total study population

\begin{tabular}{|c|c|c|c|c|c|c|c|}
\hline \multirow{2}{*}{ SNP } & \multirow{2}{*}{ Genotype } & \multicolumn{2}{|c|}{ Cases } & \multicolumn{2}{|c|}{ Controls } & \multirow{2}{*}{$\begin{array}{c}\text { Crude OR } \\
(95 \% \mathrm{CI})\end{array}$} & \multirow{2}{*}{$\begin{array}{l}\text { Adjusted OR* } \\
\quad(95 \% \mathrm{CI})\end{array}$} \\
\hline & & $\mathbf{N}$ & $\%$ & $\mathrm{~N}$ & $\%$ & & \\
\hline \multirow[t]{4}{*}{ TP53 rs2078486 } & & 355 & & 448 & & & \\
\hline & CC & 186 & 52.4 & 250 & 55.8 & 1 & 1 \\
\hline & $\mathrm{TC}$ & 136 & 38.3 & 167 & 37.3 & $1.10(0.82,1.47)$ & $1.20(0.88,1.64)$ \\
\hline & $\pi$ & 33 & 9.3 & 31 & 6.9 & $1.43(0.85,2.42)$ & $1.30(0.75,2.25)$ \\
\hline Dominant model & Any T vs. CC & 169 & 47.6 & 198 & 44.2 & $1.15(0.87,1.52)$ & $1.22(0.91,1.63)$ \\
\hline Recessive model & $\Pi$ vs. Any $C$ & 33 & 9.3 & 31 & 6.9 & $1.38(0.83,2.30)$ & $1.20(0.70,2.06)$ \\
\hline Allele OR & T vs. C & & & & & $1.15(0.93,1.43)$ & $1.17(0.93,1.46)$ \\
\hline \multirow[t]{4}{*}{ TP53 rs 1042522} & & 363 & & 446 & & & \\
\hline & GG & 118 & 32.5 & 161 & 36.1 & 1 & 1 \\
\hline & CG & 146 & 40.2 & 196 & 43.9 & $1.02(0.74,1.40)$ & $1.07(0.77,1.50)$ \\
\hline & CC & 99 & 27.3 & 89 & 20.0 & $1.52(1.05,2.20)$ & $1.63(1.10,2.41)$ \\
\hline Dominant model & Any C vs. GG & 245 & 67.5 & 285 & 63.9 & $1.17(0.88,1.57)$ & $1.24(0.92,1.69)$ \\
\hline Recessive model & CC vs. Any G & 99 & 27.3 & 89 & 20.0 & $1.50(1.08,2.09)$ & $1.57(1.11,2.21)$ \\
\hline Allele OR & C vs. G & & & & & $1.21(1.01,1.46)$ & $1.26(1.04,1.53)$ \\
\hline
\end{tabular}

*Adjusted for age, gender, education, pack years of smoking, alcohol drinking, tea drinking and average income 10 years ago. Significant results were highlighted in bold.

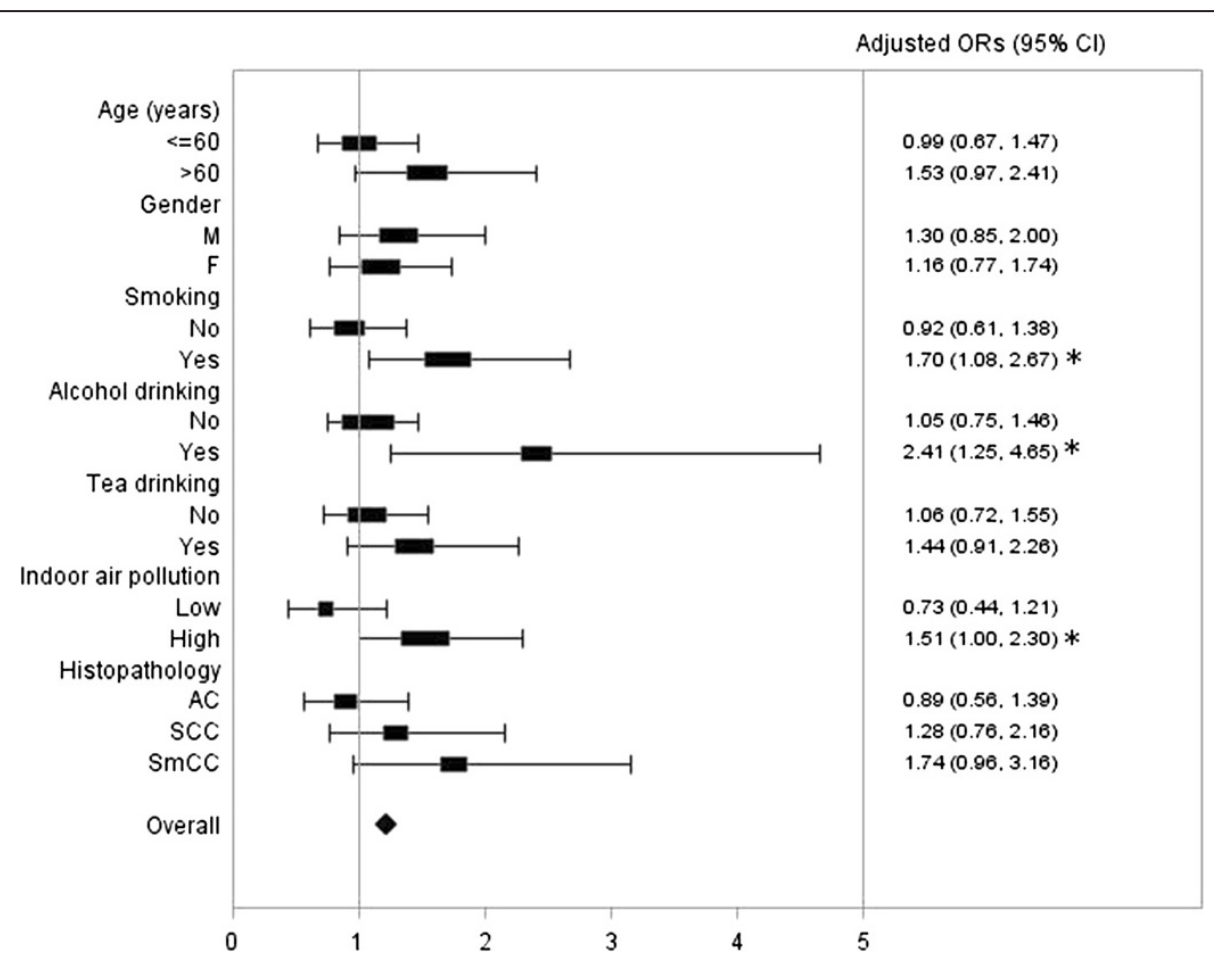

Figure 1 Associations of TP53 rs2078486 with lung cancer among different subgroups with different age, gender, smoking status, alcohol and tea drinking status, indoor air pollution exposure and histo-pathological types of lung cancer. Adjusted age, gender, education, pack years of smoking, alcohol drinking, tea drinking and average income 10 years ago. AC: adenocarcinoma, SCC: squamous cell carcinoma; SmCC: small cell carcinoma. Asterisks indicate significant ORs. 
0.99-3.30) and additive interaction (adjusted RERI: 2.49, 95\% CI: -0.03, 5.01) (Table 3).

Elevated risk of lung cancer associated with homozygous variant genotype (CC) of TP53 SNP rs1042522 were observed in each subgroup. No obvious difference was observed between smokers and nonsmokers (Figure 2). The variant genotype of TP53 SNP rs1042522 tended to confer stronger deleterious effect for younger individuals, males, alcohol and tea drinkers, however neither multiplicative nor additive interactions were observed between TP53 SNP rs1042522 and any lifestyle factors on lung cancer risk (Table 3).

\section{Discussion}

This case-control study confirmed elevated lung cancer risk associated with the variant allele (C) of TP53 SNP rs1042522, and this study is among the first to report a tendency of increased lung cancer risk associated with variant genotype of TP53 SNP rs2078486 in an Asian population. Moreover, we found synergetic effects of smoking and indoor air pollution exposure with TP53 SNP rs2078486 on lung cancer risk.

Overwhelming evidence suggested that the TP53 tumor suppressor gene is a central regulatory node of multiple cellular response pathways to endogenous or exogenous stresses [20]. P53 protein has demonstrated the capacity to regulate activity of key effectors of cellular processes, such as DNA repair, cell cycle arrest, senescence, and apoptosis [21,22]. Functional inactivation of P53 pathways is thought to affect P53 signaling and further alter cancer risk $[20,23]$.

TP53 rs2078486 SNP might be a novel TP53 SNP affecting risk of developing lung cancer. One pathwaybased genotyping study conducted among nonsmokers found statistically significant association between TP53 rs2078486 SNP and lung cancer [10]. In the present study, we found some suggestive evidence of elevated lung cancer risk associated with TC or CC genotypes of TP53 rs2078486 SNP (adjusted OR: 1.22, 95\% CI: 0.91 1.63) in the overall study participants. Our result was in similar direction with one population-based case-control study conducted in Los Angeles (adjusted OR: 1.61, 95\% CI: $1.18-2.20$ ) [11]. The less significant association observed in our study might relate to the relatively smaller sample size. Some other case-control studies also suggested that variant genotype of TP53 rs2078486 SNP was significantly associated with increased risks of ovarian cancer and schizophrenia [13,14,24]. Therefore, this suggests that there might be a functional difference among different genotypes of TP53 rs2078486 SNP, which may affect the risk of developing various types of cancers and other human diseases.

TP53 rs2078486 is located in intron 1 and thus is not likely to be a direct disease-causing polymorphism.
However previous studies suggest that TP53 rs2078486 is in a large linkage disequilibrium block extending from upstream of exon 1 to the first half of intron 1 [17]. Therefore it is possible that TP53 rs2078486 might be in linkage disequilibrium with some functional polymorphisms, which in turn alter susceptibility to human diseases. Some other intronic variations in TP53 were reported to affect disease risk previously and the most widely studied one is TP53 intron 3 duplication polymorphism (rs17878362) [5,25]. The underlying mechanism by which TP53 rs2078486 modulates cancer risk is not fully understood and warrants further investigations. However prior studies provided some initial evidence that TP53 rs2078486 is in perfect linkage disequilibrium with TP53 rs2287498, which is predicted to affect function at a splice site and TP53 rs2078486 is also in weak linkage disequilibrium with TP53 rs12951953, which might affect a transcription factor binding site [13].

Moreover, we found carrying the variant alleles of TP53 rs2078486 SNP was significantly associated with elevated lung cancer risk in smokers (adjusted OR: 1.70, 95\% CI: 1.08 - 2.67) and individuals with high indoor air pollution exposure (adjusted OR: 1.51, 95\% CI: 1.002.30). Cigarette smoking and air pollution have been linked with high frequency of TP53 mutations [26-29]. The positive interactions observed between TP53 SNP rs2078486 with smoking and indoor air pollution exposure in our study might suggest that individuals carrying the variant genotype of TP53 rs2078486 may have compromised P53 function and respond poorly to the adverse effects of smoking and air pollution, thus have an elevated risk of developing lung cancer. In addition, the elevated risk associated with high-risk genotypes TP53 rs2078486 SNP was more evident for the small cell carcinoma, which has been more strongly linked to cigarette smoking than the other histo-pathological types of lung cancer.

Elevated lung cancer risk associated with the variant $\mathrm{C}$ allele of TP53 SNP rs1042522 observed in this study was consistent with previous studies conducted among the Asian populations (summarized OR under recessive genetic model: 1.37, 95\% CI: 1.20 - 1.57; homozygote comparison CC vs. GG: 1.34, 95\% CI: 1.16 - 1.56) [8]. In the present study, we did not find heterogeneity of lung cancer risks associated with TP53 SNP rs1042522 in smokers versus non-smokers, which was also consistent with a previous meta-analysis [8]. Very few prior studies have examined if demographic or other lifestyle factors might modify the association between TP53 SNP rs1042522 and lung cancer. In this study, we did not find statistically significant interactions between lifestyle factors and TP53 SNP rs1042522 on lung cancer risk.

One major limitation of the present study is that the relatively small sample size, especially in the stratified 
Table 3 Interaction between TP53 SNPs and lifestyle factors in Taiyuan lung cancer study

\begin{tabular}{|c|c|c|c|c|c|}
\hline & & Cases & Controls & Crude OR $(95 \% \mathrm{Cl})$ & Adjusted OR* $(95 \% \mathrm{Cl})$ \\
\hline Smoking & rs2078486 & & & & \\
\hline No & CC & 95 & 147 & 1 & 1 \\
\hline No & $\mathrm{TC}$ or $\mathrm{TT}$ & 70 & 127 & $0.85(0.58,1.26)$ & $0.93(0.62,1.39)$ \\
\hline Yes & $\mathrm{CC}$ & 91 & 103 & $1.37(0.93,2.00)$ & $3.58(2.02,6.36)$ \\
\hline Yes & $\mathrm{TC}$ or $\mathrm{TT}$ & 99 & 71 & $2.16(1.45,3.22)$ & $6.00(3.33,10.81)$ \\
\hline OR for interaction & & & & $1.85(1.05,3.27)$ & $1.80(0.99,3.30)$ \\
\hline RERI & & & & $0.94(0.14,1.74)$ & $2.49(-0.03,5.01)$ \\
\hline Alcohol drinking & rs2078486 & & & & \\
\hline No & $\mathrm{CC}$ & 147 & 184 & 1 & 1 \\
\hline No & $\mathrm{TC}$ or $\mathrm{TT}$ & 124 & 148 & $1.05(0.76,1.45)$ & $1.06(0.76,1.48)$ \\
\hline Yes & $\mathrm{CC}$ & 39 & 66 & $0.74(0.47,1.16)$ & $0.71(0.42,1.21)$ \\
\hline Yes & $\mathrm{TC}$ or TT & 45 & 50 & $1.13(0.71,1.78)$ & $1.35(0.79,2.30)$ \\
\hline OR for interaction & & & & $1.45(0.76,2.78)$ & $1.79(0.90,3.58)$ \\
\hline RERI & & & & $0.34(-0.27,0.95)$ & $0.58(-0.15,1.30)$ \\
\hline Tea drinking & rs2078486 & & & & \\
\hline Yes & $\mathrm{CC}$ & 65 & 107 & 1 & 1 \\
\hline Yes & $\mathrm{TC}$ or TT & 75 & 91 & $1.36(0.88,2.09)$ & $1.44(0.91,2.28)$ \\
\hline No & $\mathrm{CC}$ & 121 & 143 & $1.39(0.94,2.06)$ & $1.43(0.92,2.22)$ \\
\hline No & $\mathrm{TC}$ or $\mathrm{TT}$ & 94 & 107 & $1.45(0.96,2.19)$ & $1.51(0.94,2.41)$ \\
\hline OR for interaction & & & & $0.77(0.43,1.35)$ & $0.73(0.40,1.32)$ \\
\hline RERI & & & & $-0.30(-1.08,0.48)$ & $-0.37(-1.21,0.48)$ \\
\hline Indoor air pollution & rs2078486 & & & & \\
\hline Low & $\mathrm{CC}$ & 63 & 124 & 1 & 1 \\
\hline Low & $\mathrm{TC}$ or TT & 41 & 105 & $0.77(0.48,1.23)$ & $0.78(0.48,1.28)$ \\
\hline High & CC & 107 & 122 & $1.73(1.16,2.57)$ & $1.42(0.92,2.20)$ \\
\hline High & $\mathrm{TC}$ or $\mathrm{TT}$ & 104 & 89 & $2.30(1.52,3.48)$ & $2.11(1.35,3.29)$ \\
\hline OR for interaction & & & & $1.73(0.94,3.18)$ & $1.89(1.00,3.56)$ \\
\hline RERI & & & & $0.81(-0.03,1.65)$ & $0.90(0.11,1.70)$ \\
\hline Smoking & rs1042522 & & & & \\
\hline No & GG or CG & 120 & 216 & 1 & 1 \\
\hline No & $C C$ & 48 & 58 & $1.49(0.96,2.32)$ & $1.59(1.00,2.53)$ \\
\hline Yes & GG or CG & 144 & 141 & $1.84(1.33,2.54)$ & $4.73(2.78,8.04)$ \\
\hline Yes & $\mathrm{CC}$ & 51 & 31 & $2.96(1.80,4.88)$ & $8.00(4.08,15.71)$ \\
\hline OR for interaction & & & & $1.08(0.55,2.11)$ & $1.07(0.52,2.18)$ \\
\hline RERI & & & & $0.63(-0.87,2.14)$ & $2.69(-1.64,7.02)$ \\
\hline Alcohol drinking & rs 1042522 & & & & \\
\hline No & GG or CG & 200 & 263 & 1 & 1 \\
\hline No & $\mathrm{CC}$ & 74 & 69 & $1.41(0.97,2.05)$ & $1.45(0.98,2.14)$ \\
\hline Yes & GG or CG & 64 & 94 & $0.90(0.62,1.29)$ & $0.90(0.57,1.41)$ \\
\hline Yes & $\mathrm{CC}$ & 25 & 20 & $1.64(0.89,3.04)$ & $1.86(0.92,3.76)$ \\
\hline OR for interaction & & & & $1.30(0.61,2.80)$ & $1.44(0.63,3.27)$ \\
\hline RERI & & & & $0.34(-0.78,1.45)$ & $0.52(-0.82,1.86)$ \\
\hline
\end{tabular}

Tea drinking

rs1042522

Yes

GG or CG

100

159 
Table 3 Interaction between TP53 SNPs and lifestyle factors in Taiyuan lung cancer study (Continued)

\begin{tabular}{|c|c|c|c|c|c|}
\hline Yes & $C C$ & 41 & 35 & $1.86(1.11,3.12)$ & $2.09(1.21,3.61)$ \\
\hline No & GG or CG & 164 & 198 & $1.32(0.95,1.82)$ & $1.39(0.95,2.04)$ \\
\hline No & CC & 58 & 54 & $1.71(1.09,2.67)$ & $1.81(1.10,2.97)$ \\
\hline OR for interaction & & & & $0.70(0.36,1.36)$ & $0.62(0.31,1.25)$ \\
\hline RERI & & & & $-0.47(-1.62,0.68)$ & $-0.67(-1.99,0.65)$ \\
\hline Indoor air pollution & rs1042522 & & & & \\
\hline Low & GG or CG & 73 & 188 & 1 & 1 \\
\hline Low & $C C$ & 33 & 41 & $2.07(1.22,3.53)$ & $1.99(1.14,3.48)$ \\
\hline High & GG or CG & 159 & 163 & $2.51(1.78,3.56)$ & $2.04(1.40,2.99)$ \\
\hline High & $C C$ & 56 & 46 & $3.14(1.95,5.04)$ & $2.76(1.66,4.58)$ \\
\hline OR for interaction & & & & $0.60(0.30,1.21)$ & $0.68(0.33,1.41)$ \\
\hline RERI & & & & $-0.45(-2.14,1.24)$ & $-0.28(-1.88,1.33)$ \\
\hline
\end{tabular}

*Adjusted for age, gender, education, pack years of smoking, alcohol drinking, tea drinking and average income 10 years ago. Significant results were highlighted in bold.

analyses, limited our ability to detect moderate interactions. Large-scale epidemiological studies are needed in the future to confirm our findings. Second, after conducting Bonferroni correction for multiple comparisons, no significant interactions between lifestyle factors and TP53 rs2078486 SNP remained; therefore we cannot exclude the possibility of spurious associations due to multiple comparisons. Lastly, recall bias is likely for established or probable risk factors of lung cancer, such as smoking and air pollution, in a case-control study. However the association between smoking and lung cancer observed in the current study is similar to the previous studies conducted in an Asian population [30]. To minimize the possible recall bias on indoor air pollution exposure, we collected information on several relevant variables, such as cooking, heating and window opening behaviors.

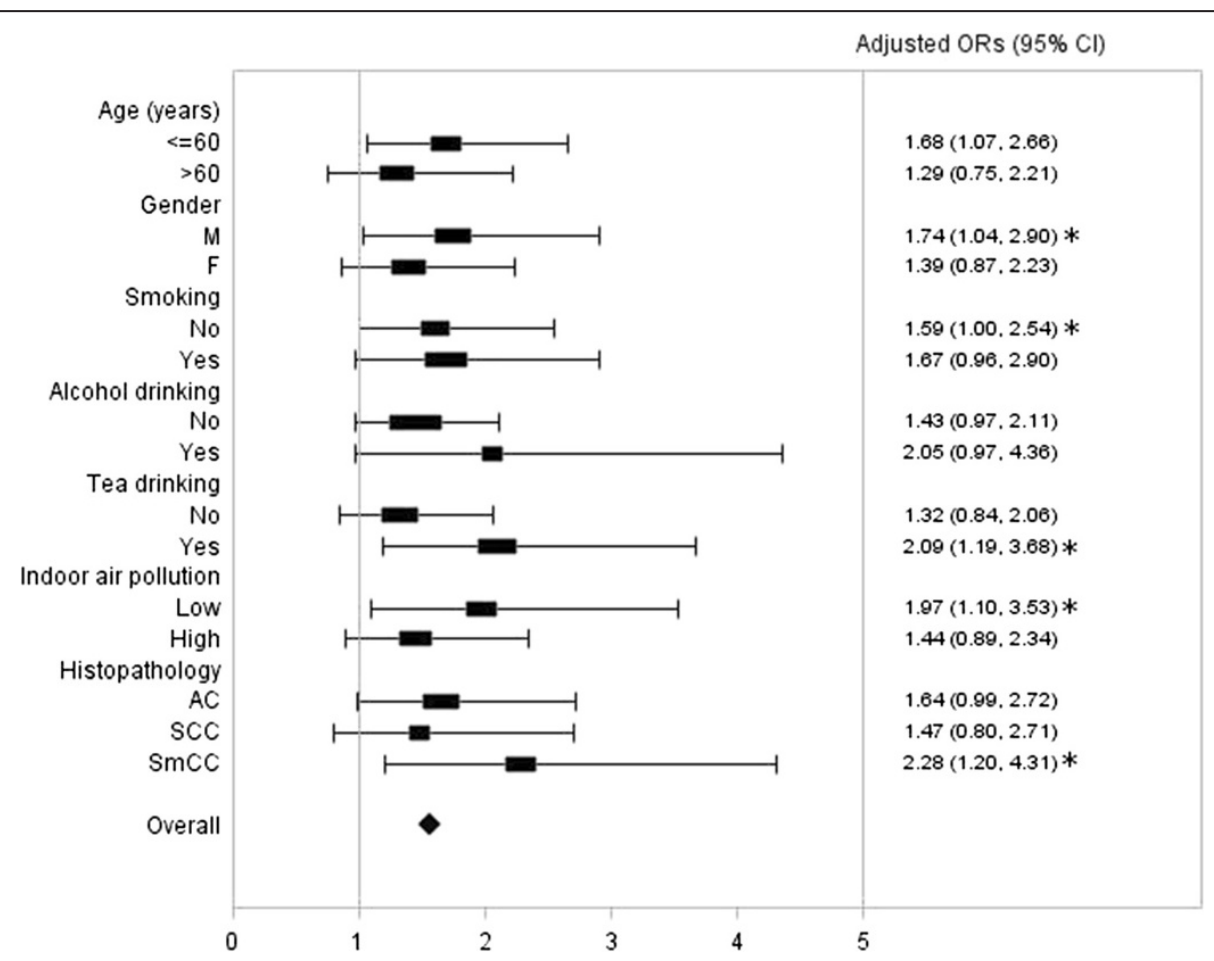

Figure 2 Associations of TP53 rs1042522 with lung cancer among different subgroups with different age, gender, smoking status, alcohol and tea drinking status, indoor air pollution exposure and histo-pathological types of lung cancer. Asterisks indicate significant ORs. AC: adenocarcinoma, SCC: squamous cell carcinoma; SmCC: small cell carcinoma. Adjusted age, gender, education, pack years of smoking, alcohol drinking, tea drinking and average income 10 years ago. 


\section{Conclusions}

In conclusion, this case-control study provided preliminary evidence that TP53 rs2078486 SNP is a novel TP53 SNP that may affect lung cancer risk, especially among smokers and individuals with high indoor air pollution exposure. There is some further evidence of significant interactions between TP53 rs2078486 SNP and smoking and indoor air pollution exposure on lung cancer risk. Further studies with larger sample size and in different study populations are warranted to confirm our findings.

\section{Abbreviations}

SNPs: Single-nucleotide polymorphisms; ORs: Odds ratios; 95\% Cls: 95\% confidence intervals; RERI: Relative excess risk due to interaction.

\section{Competing interests}

The authors declare that they have no competing interests.

\section{Authors' contributions}

YL performed the statistical analysis and drafted the manuscript. SC carried out the genetic polymorphism tests and helped to draft the manuscript. RN, $L L, B Z$, JS and XH have made substantial contributions to fieldwork and data collection. CC helped to draft the manuscript. JL, JS and LC participated in the design and coordination of the study. SY and ZZ participated in the design and fieldwork of the study. LM oversaw the study design, results interpretation and manuscript drafting. All authors read and approved the final manuscript.

\section{Acknowledgements}

This work was supported in part by the National Nature Science Foundation of China grant award to Dr. Lina Mu (NSFC-30500417). The work is also partially supported by NIH grants (R01ES018846, ES06718, CA09142, DA11386) and the Alper Research Center for Environmental Genomics of the UCLA Jonsson Comprehensive Cancer Center.

\section{Author details}

'Department of Social and Preventive Medicine, School of Public Health and Health Professions, The State University of New York (SUNY) at Buffalo, 273A Farber Hall, Buffalo, New York 14214-8001, USA. ${ }^{2}$ Department of Epidemiology, Fielding School of Public Health, University of California, Los Angeles (UCLA), Los Angeles, CA, USA. 'Shanxi Tumor Hospital, Taiyuan, Shanxi, Province, China. ${ }^{4}$ Taiyuan City Center for Disease Control and Prevention (CDC), Taiyuan, Shanxi, Province, China. ${ }^{5}$ School of Public Health, Fudan University, Shanghai, China. ${ }^{6}$ Department of Epidemiology, School of Public Health, Fujian Medical University, Fuzhou, Fijian, China.

Received: 25 March 2013 Accepted: 18 December 2013 Published: 27 December 2013

\section{References}

1. Parkin DM, Bray F, Ferlay J, Pisani P: Global cancer statistics, 2002. CA Cancer J Clin 2005, 55(2):74-108.

2. Zhao P, Dai M, Chen W, Li N: Cancer trends in China. Jpn J Clin Oncol 2010, 40(4):281-285

3. Lam WK, White NW, Chan-Yeung MM: Lung cancer epidemiology and risk factors in Asia and Africa. Int J Tuberc Lung Dis 2004, 8(9):1045-1057.

4. Kiyohara C, Otsu A, Shirakawa T, Fukuda S, Hopkin JM: Genetic polymorphisms and lung cancer susceptibility: a review. Lung Cancer 2002, 37(3):241-256.

5. Whibley C, Pharoah PD, Hollstein M: p53 polymorphisms: cancer implications. Nat Rev Cancer 2009, 9(2):95-107.

6. Grochola LF, Zeron-Medina J, Meriaux S, Bond GL: Single-nucleotide polymorphisms in the p53 signaling pathway. Cold Spring Harb Perspect Biol 2010, 2(5):a001032.

7. Francisco G, Menezes PR, Eluf-Neto J, Chammas R: Arg72Pro TP53 polymorphism and cancer susceptibility: a comprehensive meta-analysis of 302 case-control studies. Int J Cancer 2011, 129(4):920-930.
8. Yan L, Zhang D, Chen C, Mao Y, Xie Y, Li Y, Huang Y, Han B: TP53 Arg72Pro polymorphism and lung cancer risk: a meta-analysis. Int J Cancer 2009, 125(12):2903-2911.

9. Bellini MF, Cadamuro AC, Succi M, Proenca MA, Silva AE: Alterations of the TP53 gene in gastric and esophageal carcinogenesis. J Biomed Biotechnol 2012, 2012:891961.

10. Spitz MR, Gorlov IP, Amos Cl, Dong Q, Chen W, Etzel CJ, Gorlova OY, Chang DW, Pu X, Zhang D, et al: Variants in inflammation genes are implicated in risk of lung cancer in never smokers exposed to second-hand smoke. Cancer Discov 2011, 1(5):420-429.

11. Wang YR, Zhang Z, Wang YR, Zhang Z-F: Genetic variations in double-strand break DNA repair pathway and lung cancer upper \& aerodigestive tract cancer. 3446869. Los Angeles: University of California; 2010.

12. Kazma R, Babron MC, Gaborieau V, Genin E, Brennan P, Hung RJ, McLaughlin JR, Krokan HE, Elvestad MB, Skorpen F, et al: Lung cancer and DNA repair genes: multilevel association analysis from the International Lung Cancer Consortium. Carcinogenesis 2012, 33(5):1059-1064.

13. Schildkraut JM, Iversen ES, Wilson MA, Clyde MA, Moorman PG, Palmieri RT, Whitaker R, Bentley RC, Marks JR, Berchuck A: Association between DNA damage response and repair genes and risk of invasive serous ovarian cancer. PLoS One 2010, 5(4):e10061.

14. Yang Y, Xiao Z, Chen W, Sang H, Guan Y, Peng Y, Zhang D, Gu Z, Qian M, He G, et al: Tumor suppressor gene TP53 is genetically associated with schizophrenia in the Chinese population. Neurosci Lett 2004, 369(2):126-131.

15. Matlashewski GJ, Tuck S, Pim D, Lamb P, Schneider J, Crawford LV: Primary structure polymorphism at amino acid residue 72 of human p53. Mol Cell Biol 1987, 7(2):961-963.

16. Mu L, Liu L, Niu R, Zhao B, Shi J, Li Y, Swanson M, Scheider W, Su J, Chang SC, et al: Indoor air pollution and risk of lung cancer among Chinese female non-smokers. Cancer Causes Control 2013, 24(3):439-450.

17. Ortiz-Cuaran S, Cox D, Villar S, Friesen MD, Durand G, Chabrier A, Khuhaprema T, Sangrajrang S, Ognjanovic S, Groopman JD, et al: Association between TP53 R249S mutation and polymorphisms in TP53 intron 1 in hepatocellular carcinoma. Genes Chromosomes Cancer 2013, 52(10):912-919.

18. Pangilinan F, Molloy AM, Mills JL, Troendle JF, Parle-McDermott A, Signore C, O'Leary VB, Chines P, Seay JM, Geiler-Samerotte K, et al: Evaluation of common genetic variants in 82 candidate genes as risk factors for neural tube defects. BMC Med Genet 2012, 13:62.

19. Andersson T, Alfredsson L, Kallberg H, Zdravkovic S, Ahlbom A: Calculating measures of biological interaction. Eur J Epidemiol 2005, 20(7):575-579.

20. Robles Al, Linke SP, Harris CC: The p53 network in lung carcinogenesis. Oncogene 2002, 21(45):6898-6907.

21. Levine AJ: p53, the cellular gatekeeper for growth and division. Cell 1997, 88(3):323-331.

22. Riley $T$, Sontag $E$, Chen $P$, Levine A: Transcriptional control of human p53-regulated genes. Nat Rev Mol Cell Biol 2008, 9(5):402-412.

23. Moll UM, Schramm LM: p53-an acrobat in tumorigenesis. Crit Rev Oral Biol Med 1998, 9(1):23-37.

24. Schildkraut JM, Goode EL, Clyde MA, Iversen ES, Moorman PG, Berchuck A, Marks JR, Lissowska J, Brinton L, Peplonska B, et al: Single nucleotide polymorphisms in the TP53 region and susceptibility to invasive epithelial ovarian cancer. Cancer Res 2009, 69(6):2349-2357.

25. Sagne C, Marcel V, Amadou A, Hainaut P, Olivier M, Hall J: A meta-analysis of cancer risk associated with the TP53 intron 3 duplication polymorphism (rs17878362): geographic and tumor-specific effects. Cell Death Differ 2013, 4(2):e492.

26. Husgafvel-Pursiainen $K$, Kannio A: Cigarette smoking and p53 mutations in lung cancer and bladder cancer. Environ Health Perspect 1996, 104(Suppl 3):553-556.

27. Pfeifer GP, Denissenko MF, Olivier M, Tretyakova N, Hecht SS, Hainaut P: Tobacco smoke carcinogens, DNA damage and p53 mutations in smoking-associated cancers. Oncogene 2002, 21(48):7435-7451.

28. Dagher Z, Garcon G, Billet S, Gosset P, Ledoux F, Courcot D, Aboukais A, Shirali P: Activation of different pathways of apoptosis by air pollution particulate matter (PM2.5) in human epithelial lung cells (L132) in culture. Toxicology 2006, 225(1):12-24.

29. Soberanes S, Panduri V, Mutlu GM, Ghio A, Bundinger GR, Kamp DW: p53 mediates particulate matter-induced alveolar epithelial cell 
mitochondria-regulated apoptosis. Am J Respir Crit Care Med 2006, 174(11):1229-1238.

30. Wakai K, Inoue M, Mizoue T, Tanaka K, Tsuji I, Nagata C, Tsugane S: Tobacco smoking and lung cancer risk: an evaluation based on a systematic review of epidemiological evidence among the Japanese population. Jpn J Clin Oncol 2006, 36(5):309-324.

doi:10.1186/1471-2407-13-607

Cite this article as: Li et al:: TP53 genetic polymorphisms, interactions with lifestyle factors and lung cancer risk: a case control study in a Chinese population. BMC Cancer 2013 13:607.

\section{Submit your next manuscript to BioMed Central} and take full advantage of:

- Convenient online submission

- Thorough peer review

- No space constraints or color figure charges

- Immediate publication on acceptance

- Inclusion in PubMed, CAS, Scopus and Google Scholar

- Research which is freely available for redistribution 